\title{
Local-scale topoclimate effects on treeline elevations: A country-wide investigation of New Zealand's southern beech treelines
}

Bradley S Case, Hannah L Buckley

Although treeline elevations are limited globally by growing season temperature, at regional scales treelines frequently deviate below their climatic limit. The cause of these deviations relate to a host of climatic, disturbance, and geomorphic factors that operate at multiple scales. The ability to disentangle the relative effects of these factors is currently hampered by the lack of reliable topoclimatic data, which describe how regional climatic characteristics are modified by topographic effects in mountain areas. In this study we present an analysis of the combined effects of local- and regional-scale factors on southern beech treeline elevation variability at 28 study areas across New Zealand. We apply a mesoscale atmospheric model to generate local-scale $(200 \mathrm{~m})$ meteorological data at these treelines and, from these data, we derive a set of topoclimatic indices that reflect possible detrimental and ameliorative influences on tree physiological functioning. Principal components analysis of meteorological data revealed geographic structure in how study areas were situated in multivariate space along gradients of topoclimate. Random forest and conditional inference tree modelling enabled us to tease apart the relative effects of 17 explanatory factors on local-scale treeline elevation variability. Overall, modelling explained about $50 \%$ of the variation in treeline elevation variability across the 28 study areas, with local landform and topoclimatic effects generally outweighing those from regional-scale factors across the 28 study areas. Further, the nature of the relationships between treeline elevation variability and the explanatory variables were complex, frequently non-linear, and consistent with the treeline literature. To our knowledge, this is the first study where model-generated meteorological data, and derived topoclimatic indices, have been developed and applied to explain treeline variation. Our results demonstrate the potential of such an approach for ecological research in mountainous environments. 
1 Local-scale topoclimate effects on treeline elevations: A country-wide investigation of New

2

3

4

5

6

7

8

9

10

\section{Zealand's southern beech treelines}

Bradley S. Case ${ }^{1 *}$, Hannah L. Buckley ${ }^{2}$

${ }^{1}$ Department of Informatics and Enabling Technologies, Lincoln University, Lincoln, New

Zealand

${ }^{2}$ Department of Ecology, Lincoln University, Lincoln, New Zealand

*Author for correspondence: Bradley Case, Bradley.Case@lincoln.ac.nz 


\section{INTRODUCTION}

12 The tree limit, the uppermost elevation at which trees can survive, is a global bioclimatic

13 phenomenon ultimately determined by growing season temperature (Körner \& Paulsen, 2004).

14 However, treelines can often deviate below this potential climatic treeline, due to the influence of

15 factors that operate at multiple spatial scales (Holtmeier \& Broll, 2005; Malanson et al., 2011;

16 Case \& Duncan, 2014). These factors include: differences in regional climate regime (heat and

17 moisture) that affect tree growth and mediate finer-scale influences on treeline (Daniels \&

18 Veblen, 2003); disturbances, such as avalanches and landslides (Daniels \& Veblen, 2003;

19 Leonelli, Pelfini \& Cella, 2009; Case \& Hale, 2015); spatial variation in the distribution of moisture and nutrients related to geomorphology (Butler et al., 2007), and local-scale climatic variability related to topography ('topoclimate') (Holtmeier \& Broll, 2005). Thus, there is a growing recognition that in order to understand how treelines may respond regionally to climatic change, datasets and methods will be required for characterising and modelling influences on treelines at a range of scales and across large areas (Holtmeier \& Broll, 2007).

It is relatively easy to obtain GIS-ready datasets, such as gridded climatic and topographic data, for investigating influences on treelines at a regional scale (e.g. Case \& Hale, 2015). However, spatially-explicit local scale data, particularly for climatic variables, are typically more challenging to obtain. One solution is to employ topographic indices such as slope, aspect, and terrain shape, derived in a GIS from digital elevation models (DEMs), that can act as proxies for the effects of local-scale variation in environmental conditions (Moore, Grayson \& Ladson, 1991). A number of treeline studies have used DEM-derived indices in this way to highlight the important role that topography plays in influencing treeline variability (Brown, 1994; Allen \& Walsh, 1996; Walsh et al., 2003; Dullinger, Dirnböck \& Grabherr, 2004; Bader \& Ruijten, 2008). For example, Brown (1994) used three DEM-derived topographic characteristics to explain the presence of four treeline transition vegetation types. Similarly, Bader and Ruijten (2008b) found that a DEM-derived topographic index was a significant factor in explaining the presence and absence of forest within the treeline zone; the index described convex landscape zones where cold air drainage occurred and caused inverted treelines. Thus DEM-derived indices have proven useful for gaining important insights into treeline variation in cases where direct measures of local climate, disturbance and other variables have not been available. 
However, there are limits to the extent to which local-scale topoclimatic effects, in particular, can be sufficiently represented by such DEM-derived indices. Daily variation in local wind speeds, for instance, are the result of a range of meteorological processes inducing effects such as valley and downslope winds, cold air ponding, and differential irradiation, which are highly variable in space and time (Daly, Conklin \& Unsworth, 2010). Such topoclimatic phenomena are likely to have significant impacts on treelines because they can either ameliorate or exacerbate physiological functioning at the plant scale, which can have knock-on effects for recruitment above treeline (Rehm \& Feeley, 2015). Therefore, new approaches that can produce reliable topoclimatic data for local-scale treeline studies are warranted.

One such approach is to use predictive, numerical climate models that are capable of generating accurate estimates of meteorological parameters in complex terrain and that can be applied to different sites without the need for local parameterisation. A number of readilyavailable meso-scale atmospheric models are suited to this task. For example, The Air Pollution Model (TAPM) produced by CSIRO Australia (Hurley, 2008a) is a mesoscale model that has been applied at sites worldwide (Hurley, Edwards \& Luhar, 2008) and has been shown to be able to account for topographically-mediated meteorological processes such as cold air drainage and ponding in complex terrain (Hurley, Physick \& Luhar, 2005; Mocioaca, Sivertsen \& Cuculeanu, 2009; Case, Zawar-Reza \& Tait, 2015). Case et al. (2015) used TAPM to generate spatiallyexplicit meteorological data for a range of sites across New Zealand and showed that TAPM could relatively accurately simulate temperature and wind speed at these sites and that prediction accuracies were relatively consistent among sites and years for the different variables examined. Daily and monthly variation in wind speed, temperature extremes, solar radiation, and relative humidity, and interactions among these variables, together define possible topoclimatic conditions at the local treeline. These meteorological variables rarely affect treelines in isolation, but rather work synergistically to produce conditions that affect trees' physiological performance. For instance, although high winds can potentially cause direct physical damage to trees at high altitudes, this type of damage alone is typically not a critical factor in explaining treeline formation (Körner, 1998). More damaging, however, is when the action of wind combines with other topoclimatic variables to produce cumulative stressful conditions for trees over time. Such an example might be when high winds, together with high temperatures and low relative humidity during hot summer months, produce conditions where desiccation stress is 
more likely to occur (Köhler, Gieger \& Leuschner, 2006; Moyes et al., 2013). Similarly, while low night time temperatures on their own will likely have little impact on seedlings at treeline, when combined with low windspeeds and high amounts of outgoing radiation, frosts can occur that can affect leaves and buds, especially early in the growing season (Jordan \& Smith, 1994). There are also potential positive effects: for example, locations that generally have higher warmth and higher inputs of sunlight, in the absence of other stressors, might be expected to have conditions more suitable for tree establishment and growth (Cairns \& Malanson, 1998). Hence, research that is able to explore the relevance of these combined effects across different locations will be able to provide new insights into the importance of topoclimate in determining local treeline variability, relative to other local and regional influences.

In this study we provide an assessment of the importance of topoclimatic factors, relative to landform and regional environmental factors, in determining local-scale variations in treeline position for c. 2,100 treeline locations at 28 study areas across New Zealand. We focus here on southern beech (Nothofagaceae) treelines, which comprise the majority of New Zealand's treeline zones. These treelines are highly-abrupt and have had minimal above-treeline recruitment of new stems over the past 20 or more years (refs). Thus, while we acknowledge that demographic processes ultimately drive treeline formation at a given site, this study focusses specifically on among-site spatial variation in treeline elevation and the relative roles of topoclimateversus other factors in describing such variation at this spatial scale. Previous studies have highlighted the considerable variability observed in the elevation of New Zealand's southern beech (Nothofagaceae) treelines both locally and regionally, and the possible explanations for this variability (Wardle, 2008; Case \& Duncan, 2014; Case \& Hale, 2015). For example, an analysis by Case and Duncan (2014) indicated that the position of treeline varied mainly due to solar radiation and mountain mass effects at a range of scales across the country, although the coarseness of the explanatory data limited the degree to which local-scale effects could be reliably assessed. Based on field observations, Wardle $(1985,2008)$ posited that localscale variations in beech treeline elevation are related to differences in landform at treeline, with treelines reaching higher elevations on steep slopes and convex curvatures than on gentler concave forms, although the pervasiveness of this pattern across the country has not yet been empirically evaluated. We compile an explanatory dataset comprising regional-scale climate, disturbance, and landscape variability factors, local-scale DEM-derived landform factors, and a 
104 set of novel topoclimatic indices derived from meteorological data generated using the TAPM 105 meso-scale atmospheric model (Case, Zawar-Reza \& Tait, 2015). With these data we address 106 two main questions: (1) Are treelines at different locations across New Zealand characterised by 107 distinctive topoclimatic conditions?; and (2) What is the nature and extent of the effect of 108 topoclimatic stress on the variability in treeline elevation among sample points, relative to 109 landform and regional drivers?

\section{METHODS}

\section{Study areas and treeline delineation}

113 We used a GIS-based dataset delineating southern beech treelines in New Zealand (Case \&

114 Duncan, 2014). Given the abruptness of these treelines, we used available landcover data to 115 easily delineate treeline boundaries as the polygon boundaries between the "Indigenous Forest"

116 landcover class and four adjacent subalpine landcover classes (see Case \& Duncan 2014 for 117 details). Once identified, these treeline boundaries were extracted as line features in the GIS and 118 points were generated along these treelines at an average spacing of approximately $1 \mathrm{~km}$ in order 119 to capture local scale variability. These points formed the basic unit for extracting the elevation, 120 meteorological and landform data at treeline that were used for subsequent analyses. Next, we 121 chose 28 treeline study areas across the country as a basis for atmospheric modelling with the 122 TAPM model (Fig. 1). Study areas were $7 \times 7-\mathrm{km}\left(49-\mathrm{km}^{2}\right)$ in size and were randomly located 123 across southern beech treeline zones from approximately $46^{\circ} \mathrm{S}$ latitude in the south of the country 124 to $39^{\circ} \mathrm{S}$ latitude in the north. Study area dimensions were determined by the requirements of the 125 TAPM model and its application for our research aims (see below). The mean distance from each 126 site location to the next closest site was $32.4-\mathrm{km}$. To verify that all treeline point locations within 127 these study areas were actually located at treeline, we visually assessed sample points against 128 georeferenced, 15-m resolution, SPOT 5 satellite imagery (Fig. 1, inset). Points that were not 129 within 50-m of the treeline seen on the imagery were manually re-positioned to the nearest 130 treeline edge; those that could not be verified as being at treeline due to the presence of shadow 131 or cloud in the imagery, were removed from the dataset. This process resulted in a total of 2,189 132 points located at treeline across the 28 study areas.

Datasets 
135 Treeline elevation data: At each study area, we assumed that the treeline observation occurring 136 at the highest elevation provided a reasonable index of the potential, climatically-driven treeline

137 in that locale. Thus, in the absence of disturbances and topoclimatic stressors, all treelines in the

138 vicinity should reach this maximum observed local elevation due to the theoretical dominant

139 effect of mean growing season temperature (Körner \& Paulsen, 2004). Based on this assumption,

140 the difference in observed treeline elevations at each sample location from their site-level

141 maximum ("elevation deviation from maximum") was computed and used as the response

142 variable in statistical analyses. This response variable also provided a standardised measure of

143 treeline variability across the 28 study areas in that it removed possible confounding effects due

144 to the negative trend between treeline elevation and latitude that occurs across New Zealand. To

145 calculate elevation deviations, treeline elevation at each location was extracted in the GIS from a

146 25-m resolution digital elevation model for New Zealand (Barringer, McNeill \& Pairman, 2002)

147 and then subtracted from the maximum observed treeline elevation across all locations within

148 each study area.

150 Landform variability data: Two variables, slope gradient and surface curvature, were derived

151 from DEM data to investigate the impact of landform on treeline elevation deviation. Percentage

152 slope gradient was derived from DEM data at each location using the "Slope" function within

153 ArcGIS 10.1. The slope gradient is calculated as the rate of maximum change in elevation among

154 a $3 \times 3$ neighbourhood of DEM cells surrounding a focal cell location. The degree of convexity or

155 concavity of the landsurface was derived from DEM data at each treeline location using the

156 "curvature" function within ArcGIS 10.1. This function determines surface curvature for each

157 cell of the DEM by fitting a fourth order polynomial to the elevation surface within a $3 \times 3$

158 moving window centred around a given cell location. The resulting value from this calculation is

159 either positive, signifying a convex shape, or negative signifying a concave shape (Zevenbergen

$160 \&$ Thorne, 1987).

161

162 Regional-scale environmental data: Mean values for growing season temperature, mountain 163 mass, precipitation, and earthquake intensity were extracted for each $7 \times 7-\mathrm{km}$ study area to

164 represent these potential among-site differences across New Zealand. Growing season 165 temperature and precipitation data for the study areas were extracted from 500-m resolution 
166 gridded climate layers for New Zealand (Wratt et al., 2006). A mountain mass index, which 167 represents the effect of mountain size on the regional thermal regime, was derived in the GIS by 168 determining the amount of area above 1200-m within each of the study site zones. Earthquake 169 data were extracted from a 500-m resolution spatial dataset of the expected mean peak ground 170 acceleration within a 150 year return interval, expressed as the proportion of the acceleration due 171 to gravity (Stirling, Mc Verry \& Berryman, 2002).

172

173 TAPM-generated meteorological data: The Air Pollution Model (TAPM) V.4 (Hurley, 2008a)

174 was used to generate meteorological data at the 28 study sites for the purpose of characterising 175 topoclimatic conditions. TAPM predicts three-dimensional meteorology at scales ranging from 176 relatively coarse (1000 to $1500-\mathrm{km})$ to fine $(<500-\mathrm{m})$ (see Hurley, Physick \& Luhar, 2005;

177 Hurley, 2008b for further details regarding TAPM). For this study, we ran TAPM for both 178 January and July 2002 at the 28 study areas because the treeline data were also from 2002, and

179 because we wanted to account for both winter and summer conditions in assessing topoclimatic 180 effects. Further, a previous study at these same sites in New Zealand (Case, Zawar-Reza \& Tait) 181 showed that TAPM outputs for 2002 were consistent for the overall period of 2001 to 2007 and, 182 on average, did not differ from 30-year climate normal data for maximum and minimum 183 temperature and wind speed when evaluated across all sites. Thus, we considered 2002 TAPM 184 data to be representative, particularly for exploring among-site topoclimatic variation.

185 To run TAPM at its finest resolution $(200-\mathrm{m}$ grid cells), square $7 \times 7-\mathrm{km}$ study areas 186 centred on each site location were established, resulting in the generation of meteorological 187 estimates for 1225 grid cells at each study area for each of the two months. Meteorological 188 outputs from the model comprised hourly data for screen-level $(2-\mathrm{m})$ air temperatures $\left({ }^{\circ} \mathrm{C}\right)$, 189 relative humidities (\%), and short- and long-wave radiation values (Watts $\mathrm{m}^{-2}$ ), and for wind 190 speeds at $10 \mathrm{~m}$ above the ground $\left(\mathrm{m} \mathrm{s}^{-1}\right)$. To obtain TAPM-generated data at each treeline sample 191 point, we first generated geo-referenced grids of data for each topoclimatic variable within 192 ArcGIS at each site. We then extracted these data to treeline point locations in the GIS using 193 standard raster-to-point data extraction methods.

194

\section{Derivation of topoclimatic indices}


196 Using TAPM-simulated data, we computed five topoclimatic indices that provided relative, 197 potential measures of topoclimatic stress (indices of photoinhibition, desiccation, and frost), and 198 topoclimatic amelioration (insolation) on tree physiological function at treeline. All indices were 199 computed for the months of January and July in order to determine how these indices vary in summer and winter, and if this variation is important for understanding treeline variability.

Photoinhibition index: There is considerable evidence from treeline research that

202

increased sky exposure is detrimental to seedling establishment above existing treelines (Wardle, 1985b; Ball, Hodges \& Laughlin, 1991; Germino \& Smith, 1999; Germino, Smith \& Resor, 2002; Bader, Geloof \& Rietkerk, 2007; Giménez-Benavides, Escudero \& Iriondo, 2007). This effect is typically attributed to cold-induced photoinhibition, where low temperatures and high solar radiation combine to disrupt photosynthetic functioning. To generate an index of photoinhibition, hourly temperature values $\left(T_{\text {hourly }}\right)$ were first rescaled relative to the overall observed site-level maximum temperature such that lower temperatures received a higher relative weighting in calculating the potential for photoinhibition at a given treeline location. The photoinhibition index was then calculated as the product of rescaled hourly temperatures and hourly solar radiation $\left(\right.$ SolRad $\left._{\text {hourly }}\right)$ summed across all daytime hours and divided by the number of monthly daytime hours $\left(N_{\text {daytime }}\right)$ :

Mean photoinhibition index $=\frac{\sum_{\text {daytime }}\left[\left(T_{\text {site_max }}-T_{\text {hourly }}\right) \times \text { SolRad }_{\text {hourly }}\right]}{N_{\text {daytime }}}$

Thus, locations where the combination of low temperatures and high solar radiation values were more prevalent received higher values for this index.

Summer desiccation index: Desiccation stress can occur at treeline in both summer and winter (Tranquillini, 1979; Harsch \& Bader, 2011). During hot summer months, desiccation conditions can result from the combination of relatively high daytime wind speeds and temperatures and low relative humidities. These conditions can increase cuticular transpiration rates and dry out thin soils, leading to drought stress (Cui \& Smith, 1991; Kullman, 2005). In winter months, cold temperatures periodically induce frozen soils and plant tissues, while high wind conditions and low relative humidities increase cuticular transpiration rates, thus increasing the potential for desiccation damage of treeline seedlings and trees (Baig \& Tranquillini, 1980; Wardle, 1981; Sowell, McNulty \& Schilling, 1996). High wind speeds can also exacerbate these effects by causing direct abrasion damage to the cuticles of exposed leaves, thereby increasing the potential for water loss (Hadley \& Smith, 1983). Indices of potential summer and winter 
227 desiccation conditions were calculated as the mean product of daytime hourly temperature, wind 228 speed and relative humidity data for January. For both summer and winter desiccation indices, 229 relative humidities were rescaled relative to a maximum humidity of $100 \%$ such that lower 230 humidity values contributed towards a higher desiccation index:

231 Mean summer desiccation index $=\frac{\sum_{\text {daytime }}\left[T_{\text {hourly }} \times W S_{\text {hourly }} \times\left(100-\text { RelHum }_{\text {hourly }}\right)\right]}{N_{\text {daytime }}}$

232 Winter desiccation index: This index was similarly calculated as in (2), but averaged 233 across the whole day (i.e. total number of monthly hours, $N_{\text {total }}$ ) and with temperatures rescaled 234 such that low temperatures (inducing possible frost drought conditions) contribute more to high 235 index values:

236 Mean winter desiccation index $=\frac{\sum_{\text {daytime }}\left[\left(T_{\text {site max }}-T_{\text {hourly }}\right) \times W S_{\text {hourly }} \times\left(100-\text { RelHum }_{\text {hourly }}\right)\right]}{N_{\text {total }}}$

237 Frost index: Cold night-time temperatures combined with low wind speeds and high 238 levels of outgoing, long-wave radiation can lead to frost conditions (Lindkvist, Gustavsson \& 239 Bogren, 2000). Frost damage to mature trees at treeline is rarely significant and is not considered 240 a major treeline-forming factor (Körner, 1998; Cieraad et al., 2012). However, early summer 241 frosts can cause significant damage to new leaves of seedlings (King \& Ball, 1998) and is 242 considered a potential limiting factor for the establishment of trees above existing treelines in 243 certain regions of the world (Germino \& Smith, 2000; Piper et al., 2005) including Nothofagus 244 treelines in New Zealand (Wardle, 1985a; Greer \& Buxton, 1989). A frost index was computed 245 as:

246 Frost index $=\frac{\sum_{\text {nighttime }}\left[\left(T_{\text {sitemax }}-T_{\text {hourl } y}\right) \times\left(W S_{\text {sitemax }}-W S_{\text {hourl }}\right) \times\left(-\left(\text { NetRad }_{\text {hour }}\right)\right]\right.}{\left.N_{\text {nighttime }}\right)}$

$247 T_{\text {site_max }}$ and $W S_{\text {site_max }}$ are the maximum, site-level temperature and wind speed values, and are 248 used to rescale hourly temperatures $\left(T_{\text {hourly }}\right)$ and wind speeds $\left(W S_{\text {hourly }}\right)$ to a reverse scale at each 249 site. In this way, temperatures and wind speeds that are low relative to the site-level maximum 250 for these variables contribute towards a higher frost index value, while those that approach the 251 site-level maximum contribute towards a lower frost index. NetRad ${ }_{\text {hourly }}$ is the hourly net 252 radiation, computed by TAPM as the difference between incoming solar radiation and outgoing 253 radiation emitted from the land surface; NetRad hourly values during night-time hours are negative 254 as there is no incoming solar radiation. Hourly frost index values calculated in this manner are 255 then summed across all night-time hours in each of January and July, and divided by the number 256 of monthly night-time hours for those months $\left(N_{\text {night-time }}\right)$ : 
Insolation: Differences in solar radiation loadings among treeline locations typically

258 reflect either differences in topographic orientation relative to the sun (i.e. aspect differences) or

259 differences in the amount of cloud cover over time. Insolation is a key topoclimatic variable at

260 treeline, and can exert both positive and negative effects. In general, locations with higher solar

261 radiation, that are not also subjected to cold night-time/early morning temperatures, are likely to

262 have more favourable conditions for growth due to increased warmth (Danby \& Hik, 2007a).

263 Insolation values were computed as the total daytime solar radiation at a location.

\section{Data analysis}

266 We used principal components analysis (PCA) to decompose variation in, and examine correlations among, the raw, TAPM-generated topoclimatic variables across the 28 study areas. To visualise these outputs, we plotted PCA bi-plots of axis combinations that explained at least $10 \%$ of the variation in the multivariate data; the location of study areas in ordination space were also overlain onto these bi-plots and coloured by their latitudes, to determine if topoclimatic data showed broad geographic structuring.

To investigate relationships between the response variable and the 17 explanatory factors, we used a two-stage approach: first we used random forest analysis (Breiman, 2001) to estimate and rank the importance of each explanatory factor in describing variability in the response variable; second, we used conditional inference trees to gain further insight into the nature of relationships between the response variable and most important explanatory factors. These two non-parametric, machine learning analysis methods have several benefits over linear parametric modelling methods in that they can more easily model complicated, non-linear relationships among large numbers of inter-correlated explanatory factors and a response variable (De'ath \&

280 Fabricius, 2000; Cutler, Jr \& Beard, 2007). The random forest approach is an ensemble machine learning method that averages the outcomes of thousands of boostrapped regression trees

282 ('forests') in order to generate a relative ranking of the importance of the explanatory variables in predicting the response variable across these forests. The random forest algorithm, its associated metrics, and uses in ecology are detailed in Cutler et al. (2007). We used the random

285 forest 'variable importance' measure to identify the most influential factors in explaining

286 variation in the response variable and then used partial dependence plots to show the marginal

287 effect of each of these factors on the response variable while holding all of the other explanatory 
288 factors at their average values (Cutler, Jr \& Beard, 2007). The relationships of top-ranked 289 explanatory factors with the response variable were then further investigated using conditional 290 inference trees (Hothorn, Hornik \& Zeileis, 2006), a recursive partitioning regression tree

291 method that generates a set of decision rules describing how variation in the response data is best 292 partitioned in terms of the explanatory data. The conditional inference tree method requires a 293 statistically significant difference, as determined by Monte Carlo simulation, in order to create a 294 partition in the data; this algorithm, in comparison to those used by other regression tree 295 methods, minimises bias and prevents over-fitting and the need for tree pruning (Hothorn, 296 Hornik \& Zeileis, 2006). Random forest and conditional inference tree analyses were 297 implemented in R version 3.1.0 using the 'randomForest' (Liaw \& Wiener, 2002) and 'party' 298 (Hothorn, Hornik \& Zeileis, 2006) packages, respectively.

\section{RESULTS}

Treeline elevation across the 28 study areas ranged from 763 to $1486-\mathrm{m}$ (mean elevation $=$ 1112.8-m, standard deviation $=195.5-\mathrm{m}$ ). There was a large amount of variation within and among study areas in the deviation of treeline elevations from their potential study area maxima (Fig. 2). Across study areas, treeline elevations deviated from near the study area maximum (i.e. $0-\mathrm{m}$ elevation deviation) to $500 \mathrm{~m}$ lower in elevation at some locations. For the majority of treeline locations, elevations were predominately in the range of 100 to $250 \mathrm{~m}$ lower than the maximum potential treeline.

Approximately $80 \%$ of variation in the meteorological data generated by TAPM across the treeline locations was explained by the first three principal component axes. The first principal component axis was most strongly characterised by negative loadings for January and July minimum and maximum relative humidity, rain days, and night time longwave radiation, and positive loadings for January and July solar radiation (Table 1). The second principal component axis was associated with relatively high positive loadings for January and July maximum and minimum temperatures and negative loadings for January frost hours. The third principal component axis was most strongly characterised by positive loadings for January and

317 were well-separated along these gradients and there were geographic patterns in the positioning 318 of study areas in multivariate space, although these patterns were not obviously latitudinally- 
319 driven (Fig. 3). Rather, sites were clearly separated based on dominant regional differences in 320 mountain climates in terms of warmth, moisture, windiness, solar radiation, and frostiness.

321 The random forest analysis explained approximately $50 \%$ of variation in treeline

322 elevation deviation based on the 17 explanatory factors (see Supplementary Material for

323 summary statistics). Variable importance rankings indicated that the landform variable

324 "curvature" had the largest impact in explaining variation in treeline elevation deviation across

325 all of the regression trees built by the random forest analysis (Fig. 4). Next, and essentially

326 equivalent in importance, were a group of eleven variables including slope, precipitation,

327 growing season temperature, and all of the topoclimatic indices. The remaining five regional

328 variables - mountain mass index, erosion index, earthquake intensity, and winter temperatures -

329 were clearly ranked lower in importance by the random forest algorithm; further analyses were

330 therefore focussed on the 12 top-ranked variables. Partial dependence plots suggested that

331 relationships between treeline elevation deviation and the top 12 variables were frequently non-

332 linear (Fig. 5). Deviations of treelines from their potential site-level maxima were negatively

333 associated with slope curvature, with treeline elevations deviating most greatly on increasingly

334 concave slopes. Greater deviations in treeline elevation were associated with lower, gentle slope

335 gradients, as well as with steep slopes, with the lowest deviations occurring on slopes of

336 intermediate steepness of about 50 to $100 \%$. Treelines tended to deviate more from their

337 potential maxima with increasing January and July desiccation index values. Five topoclimatic

338 indices (January and July photoinhibition and frost indices and July insolation) showed a more u-

339 shaped relationship with treeline elevation deviation, with relatively high deviations occurring

340 for both very low index values and higher index values and the lowest deviations at intermediate

341 index values. January insolation showed a negative linear association with treeline elevation

342 deviation. Annual precipitation was generally positively related to treeline deviation, with the

343 highest deviations associated with the most regionally-wet regions. Growing season temperature

344 showed a negative sigmoidal relationship with treeline deviation, with a sharp decrease from

345 high to low treeline elevation deviation occurring at intermediate growing season temperatures of 346 about 11.5 to $12.5^{\circ} \mathrm{C}$.

347 The conditional inference tree analysis produced twelve terminal nodes using six of the

34812 explanatory variables entered into the analysis: precipitation, curvature, slope gradient,

349 growing season temperature, July frost index, and July desiccation index (Fig. 6). The first 
350 partition of the response dataset was based on a regional annual precipitation threshold. In 351 general, treeline locations with greater than $5,664 \mathrm{~mm}$ per year of precipitation showed on 352 average higher deviations from their site-level maxima than locations with precipitation values

353 lower than this threshold. Both the highest and lowest treeline elevation deviation locations were 354 explained by data partitions involving interactions among precipitation, growing season temperature, curvature and July frost index (Fig. 6). While there was some within-site variability in the terminal nodes associated with each study area, there were also clear among-study area regional patterns in the location of terminal nodes (Fig. 7), similar to what emerged from the principal components analysis. For instance, nodes 19 to 23, representing locations with the highest average treeline deviations, were mainly associated with study areas 6,8,9,12, and 13 which are situated along the wetter, western side of the main divide in the South Island of New Zealand (see Fig. 1). Conversely, treeline locations closest to their potential maxima (node 13) were primarily associated with study areas in the North Island (25 to 28 ) and the very top of the South Island (22 and 24).

\section{DISCUSSION}

Although a range of previous treeline studies have used combinations of topography-based metrics and/or interpolated climatic datasets for treeline modelling (refs), the present study is the first to use model-generated meteorological data, and derived topoclimatic indices, to explain treeline variation. Hourly meteorological data generated by the TAPM model enabled the investigation of variability in a number of factors influencing treelines that are notoriously hard to quantify, particularly at local spatial scales in mountain environments. Spatially-explicit data for variables such as minimum or maximum daily temperatures, long-wave radiation, and relative humidity are key variables relevant to characterising physiological stress at treeline but, in previous studies, have been typically limited to collection by on-site data loggers. Thus, our study has demonstrated potential for the application of such methods to ecological research in mountainous areas. Modelling results indicate that half of the variation in treeline elevation deviations can be explained by a mixture of local landform and topoclimatic factors and mean regional effects of precipitation and growing season temperature. This result corroborates the idea that treeline position is driven by effects that occur at multiple spatial scales, where regional-scale climates can act to modulate or constrain local scale processes and their effects on 
381

382

383

384

385

386

387

388

389

390

391

392

393

394

395

396

397

398

399

400

401

402

403

404

405

406

407

408

409

410

411

treelines (Daniels \& Veblen 2003, Elliott \& Kipfmueller 2011, Case \& Duncan 2014). Further, the ways in which the explanatory variables predict treeline elevation deviations across our study areas appear to be geographically-structured, reinforcing the idea that distinct treeline drivers are associated with particular mountain regions (Case \& Hale, 2015).

Clear topoclimatic gradients were identified using TAPM-generated meteorological data, suggesting that there is a characteristic set of topographically-mediated processes acting across these treelines in New Zealand. Further, different treeline study areas were grouped by distinct topoclimatic conditions as represented by these gradients, likely reflecting the way in which geographic differences in mountain characteristics and regional climates drive these patterns. It is well recognised that the size of mountain ranges and their orientation relative to prevailing winds, valley widths and slope angles all affect valley-scale thermodynamic processes that regulate wind speeds, temperature extremes, and atmospheric moisture levels at different locations (Sturman \& Tapper, 2006). From a treeline research perspective, the ability to reliably identify and classify treeline study sites at more local scales in terms of their topoclimatic characteristics represents an ongoing gap in treeline research (Malanson et al., 2011), and our approach therefore shows promise in this regard. Further verification, using both field work and modelling, of the types of topoclimatic scenarios illuminated in this study would shed further light on particular aspects of topoclimatic effects at treelines.

Most of the treeline locations investigated in this study were positioned between 100 and $300 \mathrm{~m}$ below the potential study area maxima, suggesting that southern beech treelines at many locations across New Zealand are likely occurring well below their temperature-based limit. A recent GIS-based analysis of New Zealand beech treeline elevations (Case \& Duncan, 2014) showed that there was considerable country-wide variation in beech treeline position across the country. At a more local scale, Wardle's (1985a,b,c) observations of beech treelines in the South Island's Craigieburn Range suggested that treelines in this region are locally-depressed in valley heads and gullies and in other situations where fire had cause past removal of forest. However, his estimates placed these treelines $100 \mathrm{~m}$ lower, at most, than what he considered to be climatic treeline. Clearly, based on results from the present study, beech treeline positions in New Zealand are more locally-variable than previously described. Certain areas of the country in particular, such as along the spine of the lower Southern Alps, display highly depressed treeline locations. On the whole, these results highlight the benefits of carrying out analyses of treeline 
412 features over large spatial extents in order to provide an accurate characterisation of treeline 413 variability.

414 Treelines at sites located away from the wettest areas of New Zealand with relatively

415 high mean growing season temperatures $\left(>11.5-^{\circ} \mathrm{C}\right)$ were more likely to be situated closer to 416 their maximum potential elevation. Variation in these factors essentially describes differences in 417 regional thermal regimes across the 28 study areas; the effect of thermal regime on treeline 418 position in this study is consistent with previous research that has shown that warmer, drier 419 regions have higher treelines (Case \& Duncan, 2014). At more local scales, results also indicate 420 that New Zealand's beech treelines are, indeed, higher and closer to their potential maximum 421 growth limits on relatively steep, convex landform positions, consistent with Wardle's (1985c) 422 observations. This effect is contrary, however, to what is observed at many northern-hemisphere 423 treelines, where more exposed convex sites have been shown to be typically unfavourable for 424 tree establishment (Holtmeier, 2009). In the complex topography of New Zealand's mountains, 425 ridge-to-valley gully features occur regularly along valley sides and may act to channel slope426 scale air movement (Sturman \& Tapper 2006), thus enhancing the detrimental effects mentioned 427 above. Concave landform situations may also be indicative of where recurring avalanche and 428 landslide disturbances occur. Thus, it is possible that southern beech species are able to reach 429 higher elevations on convex, steeper slopes due to the more stable atmospheric and geomorphic 430 conditions in these locations. Nonetheless, our results also indicate that extremely steep slope 431 gradients $(>100 \%)$ are associated with depressed treelines, likely a reflection of the physical 432 constraints on tree establishment at such locations (Macias-Fauria \& Johnson, 2013).

433 All topoclimatic stressors and ameliorators, as defined by our topoclimatic indices, were 434 relatively highly important in explaining treeline deviations. In general, treelines deviated 435 increasingly further downhill from their potential maximum elevations with increasing 436 topoclimatic stress (ie. desiccation, photoinhibition, and frost) but were closer to their maxima at 437 locations with higher solar radiation input. The night-time movement of cold air from upper to 438 lower elevations will increase the potential for frost and early morning photoinhibition, while 439 strong daytime upslope wind movement will likely enhance desiccation conditions in both 440 summer and winter. There will therefore likely be a combined effect of these stressors in certain 441 locations at elevations lower than the maximum potential treeline. Cumulative effects can act 442 across seasons; for instance, early summer frosts may disrupt the de-hardening of leaf tissues 
443 thereby exacerbating desiccation damage during the following winter (Cochrane \& Slatyer, 444 1988). These types of stresses will act to maintain treelines locally at lower elevations, limiting 445 their advance, despite possible warmer mean temperatures relative to higher elevations. Our 446 results are also in line with field-based evidence of the detrimental effects of photoinhibition, 447 desiccation, and frost on southern beech seedlings (Sakai \& Wardle, 1973; Wardle, 1985a,b; 448 Greer, Wardle \& Buxton, 1989; Ball, Hodges \& Laughlin, 1991; Harsch, 2010), and lend support 449 to the general hypothesis that abrupt treeline boundaries form at elevations where strong effects 450 of physiological stressors on seedling establishment override the more gradual effect of 451 decreasing temperature with increasing elevation (Harsch \& Bader, 2011). Further, the positive 452 effect of solar radiation illustrated in our results has been also noted by a number of studies 453 (Danby \& Hik 2007, Elliott \& Kipfmueller 2010, Case \& Duncan 2014), although this was not 454 the case in others (Körner \& Paulsen, 2004; Treml \& Banaš, 2008). Higher summer insolation 455 will generally lead to more favourable growing conditions and, thus, produce treelines that are 456 closer to their climatically-driven maximum elevation.

457 It is well-recognised that treeline patterns are driven, in certain contexts, by non-linear, 458 threshold-like responses to underlying environmental factors (Malanson, 2001; Danby \& Hik, 459 2007b; Harsch \& Bader, 2011). In this study there were clear threshold-type responses in the 460 way treeline elevations deviated from their maxima in relation to many of the explanatory 461 variables. For instance, treelines generally deviated further from their potential maximum 462 elevations below a growing season temperature of about $11.5^{\circ} \mathrm{C}$, consistent with findings of 463 Cieraad \& McGlone (2014). Similarly, there was a clear and relatively abrupt shift of treelines 464 toward higher elevations as terrain shape switched in form from concave to flat and then to 465 convex. Further, threshold-like responses of treelines to several of the topoclimatic indices, 466 including January and July photoinhibition and frost indices and July insolation, were also 467 evident. On the whole, our results provide further evidence that specific levels of a factor, or sets 468 of factors, can invoke abrupt responses in the physiological (e.g., carbon allocation), 469 demographic (e.g., recruitment) and/or ecological (e.g., competition) mechanisms that underpin 470 treeline formation.

471 Fifty percent of the variation in treeline elevation deviation could not be explained by our 472 models; explanatory factors appeared to be most useful in predicting deviations of 300-m or less.

473 It is highly likely that treeline elevation deviations of more than 300-m were driven by local 
474 disturbances that were not well-represented by our explanatory factors. The effects of 475 disturbances, including those from fire (Ledgard \& Davis, 2004), heavy winds (Martin \& Ogden, 476 2006) and snowfalls (Wardle \& Allen, 1984), and tectonic activity (Allen, Bellingham \& Wiser,

477 1999; Haase, 1999; Vittoz, Steward \& Duncan, 2001) are widespread and significant throughout 478 southern beech forests and are apparent throughout many treeline zones (Wardle, 2008; Case \& 479 Hale, 2015). Further, southern beech species in New Zealand are generally slow to recolonise 480 areas after removal, even in lower-elevation forests, due to strong competition with other species 481 (Wiser, Allen \& Platt, 1997). Thus, disturbance may be a confounding factor at many treeline 482 sites in New Zealand and, without better datasets characterising the spatial distribution of local483 scale disturbances across the country, it may be difficult to disentangle their effects from those 484 due to climate. Further, finer scale microhabitat and microclimate effects on ecological 485 interactions are likely also very important in allowing beech seedlings to establish above current positions (Harsch et al., 2012). In the case of abrupt treelines, positive feedback processes, where established trees facilitate the recruitment of nearby seedlings through environmental modification, are critical in enabling these treelines to advance (Wiegand et al., 2006).

\section{CONCLUSIONS}

491 This study has demonstrated that models such as TAPM have potential for enabling local-scale investigations of topoclimatic effects at treeline. Clearly, two of the biggest advantages are the generation of spatially-explicit data useful for characterising stress-related effects and the ability to produce these data at any location. However, it is important to recognise that meteorological data for one year may not be representative of typical topoclimatic conditions occurring at a given location, and it would therefore be useful to average model data over longer periods and for other critical parts of the year such as late spring and early autumn. Overall, we show that landform, topoclimatic, and regional factors together can explain half the variation in local treeline elevation variation and that their influences are geographically-structured and typically non-linear in nature. Ultimately, results from this study could be used to characterise sites with different topoclimatic situations where investigations of local scale microclimate and biotic

502 interactions could be investigated.

\section{ACKNOWLEDGEMENTS}


505 We thank Richard Duncan, Roddy Hale, Timothy Curran, Peyman Zawar-Reza and the Lincoln

506 University Spatial Ecology Lab Group for reading and/or discussing earlier versions of this

507 work. We also thank the three reviewers whose useful comments greatly improved this

508 manuscript.

509

REFERENCES CITED

511

512

513

514

515

516

517

518

519

520

521

522

523

524

525

526

527

528

529

530

531

532

533

534

535

Allen RB, Bellingham PJ, Wiser SK. 1999. Immediate damage by an earthquake to a temperate montane forest. Ecology 80:708-714.

Allen TR, Walsh SJ. 1996. Spatial and compositional pattern of alpine treeline, Glacier National Park, Montana. Photogrammetric Engineering and Remote Sensing 62:1261-1268.

Bader MYM, Geloof I Van, Rietkerk M. 2007. High solar radiation hinders tree regeneration above the alpine treeline in northern Ecuador. Plant Ecology 191:33-45.

Bader M, Ruijten J. 2008. A topography-based model of forest cover at the alpine tree line in the tropical Andes. Journal of Biogeography 35:711-723.

Baig M, Tranquillini W. 1980. The effects of wind and temperature on cuticular transpiration of Picea abies and Pinus cembra and their significance in dessication damage at the alpine treeline. Oecologia 47:252-256.

Ball MC, Hodges VS, Laughlin GP. 1991. Cold-induced photoinhibition limits regeneration of snow gum at tree-line. Functional Ecology 5:663-668.

Barringer J, McNeill S, Pairman D. 2002. Progress on assessing the accuracy of a high resolution digital elevation model for New Zealand. In: 5th International Symposium on Spatial Accuracy Assessment in Natural Resources and Environmental Sciences Melbourne Australia. 10-12.

Breiman L. 2001. Random forests. Machine learning 45:5-32.

Brown DGD. 1994. Predicting vegetation types at treeline using topography and biophysical disturbance variables. Journal of Vegetation Science 5:641-656.

Butler DR, Malanson GP, Walsh SJ, Fagre DB. 2007. Influences of geomorphology and geology on alpine treeline in the American west - more important than climatic influences? Physical Geography 28:434-450.

Cairns DMD, Malanson GPG. 1998. Environmental variables influencing the carbon balance at the alpine treeline: a modeling approach. Journal of Vegetation Science 9:679-692. 
536 Case B, Duncan R. 2014. A novel framework for disentangling the scale dependent influences of abiotic factors on alpine treeline position. Ecography 37:838-851.

538

539

540

541

542

543

544

545

546

547

548

549

550

551

552

553

554

555

556

557

558

559

560

561

562

563

564

565

Case BS, Hale RJ. 2015. Using novel metrics to assess biogeographic patterns of abrupt treelines in relation to abiotic influences. Progress in Physical Geography 39:310-336.

Case BS, Zawar-Reza P, Tait A. 2015. Simulating topoclimatic data to support bioclimatic research in alpine environments: application and assessment of a mesoscale atmospheric model. International Journal of Climatology.

Cieraad E, McGlone M, Barbour MM, Huntley B. 2012. Seasonal frost tolerance of trees in the New Zealand treeline ecotone. Arctic, Antarctic, and Alpine Research 44:332-342.

Cieraad E, McGlone MS. 2014. Thermal environment of New Zealand's gradual and abrupt treeline ecotones. New Zealand Journal of Ecology 38:12-25.

Cochrane PM, Slatyer RO. 1988. Water relations of Eucalyptus pauciflora near the alpine tree line in winter. Tree Physiology 4:45-52.

Cui M, Smith WK. 1991. Photosynthesis, water relations and mortality in Abies lasiocarpa seedlings during natural establishment. Tree Physiology 8:37-46.

Cutler D, Jr TE, Beard K. 2007. Random forests for classification in ecology. Ecology.

Daly C, Conklin DR, Unsworth MH. 2010. Local atmospheric decoupling in complex topography alters climate change impacts. International Journal of Climatology 30:18571864.

Danby RK, Hik DS. 2007a. Evidence of recent treeline dynamics in southwest Yukon from aerial photographs. Arctic 60:411-420.

Danby RK, Hik DS. 2007b. Variability, contingency and rapid change in recent subarctic alpine tree line dynamics. Journal of Ecology 95:352-363.

Daniels LD, Veblen TT. 2003. Regional and local effects of disturbance and climate on altitudinal treelines in northern Patagonia. Journal of Vegetation Science 14:733-742.

De'ath G, Fabricius K. 2000. Classification and regression trees: a powerful yet simple technique for ecological data analysis. Ecology.

Dullinger S, Dirnböck T, Grabherr G. 2004. Modelling climate change-driven treeline shifts: relative effects of temperature increase, dispersal and invasibility. Journal of Ecology 92:241-252. 
566

Elliott GP, Kipfmueller KF. 2010. Multi-scale influences of slope aspect and spatial pattern on ecotonal dynamics at upper treeline in the southern Rocky Mountains, U.S.A. Arctic, Antarctic, and Alpine Research 42:45-56.

Elliott GP, Kipfmueller KF. 2011. Multiscale influences of climate on upper treeline dynamics in the southern Rocky Mountains, USA: Evidence of intraregional variability and bioclimatic thresholds in response to twentieth-century warming. Annals of the Association of American Geographers 101:1181-1203.

Germino MJ, Smith WK. 1999. Sky exposure, crown architecture, and low-temperature photoinhibition in conifer seedlings at alpine treeline. Plant Cell and Environment 22:407415.

Germino MJ, Smith WK. 2000. Differences in microsite, plant form, and low-temperature photoinhibition in alpine plants. Arctic Antarctic and Alpine Research 32:388-396.

Germino MJ, Smith WK, Resor AC. 2002. Conifer seedling distribution and survival in an alpine-treeline ecotone. Plant Ecology 162:157-168.

Giménez-Benavides L, Escudero A, Iriondo JM. 2007. Local adaptation enhances seedling recruitment along an altitudinal gradient in a high mountain mediterranean plant. Annals of Botany 99:723-734.

Greer DH, Buxton RP. 1989. Seasonal frost hardiness of Nothofagus solandri seedlings from two altitudinally diverse sites in Canterbury, New Zealand. New Zealand Journal of Botany 27:299-304.

Greer D, Wardle P, Buxton R p. 1989. Seasonal frost hardiness of Nothofagus solandri seedlings from two altitudinally diverse sites in Canterbury, New Zealand. New Zealand Journal of Botany 27:299-304.

Haase P. 1999. Regional tectonics, disturbance, and population size of isolated stands of Nothofagus fusca (Nothofagaceae) in a forest ecotone in south-western New Zealand. Journal of Biogeography 26:1091-1099.

Hadley J, Smith W. 1983. Influence of wind exposure on needle desiccation and mortality for timberline conifers in Wyoming, USA. Arctic and Alpine Research.

Harsch M. 2010. Treeline dynamics: pattern and process at multiple spatial scales. PhD Thesis, Lincoln University, Lincoln, New Zealand.

Harsch MA, Buxton R, Duncan RP, Hulme PE, Wardle P, Wilmshurst J. 2012. Causes of tree line stability: stem growth, recruitment and mortality rates over 15 years at New Zealand Nothofagus tree lines. Journal of Biogeography 39:2061-2071. 
599

600

601

602

603

604

605

606

607

608

609

610

611

612

613

614

615

616

617

618

619

620

621

622

623

624

625

626

627

628

629

Harsch MA, Bader MY. 2011. Treeline form - a potential key to understanding treeline dynamics. Global Ecology and Biogeography 20:582-596.

Holtmeier F. 2009. Mountain Timberlines. Ecology, Patchiness and Dynamics .-Advances in Global Change Res. 36. Springer.

Holtmeier F, Broll G. 2005. Sensitivity and response of northern hemisphere altitudinal and polar treelines to environmental change at landscape and local scales. Global Ecology and Biogeography 14:395-410.

Holtmeier F, Broll G. 2007. Treeline advance-driving processes and adverse factors. Landscape Online 1:1-33.

Hothorn T, Hornik K, Zeileis A. 2006. Unbiased recursive partitioning: A conditional inference framework. Journal of Computational and Graphical Statistics 15:651-674.

Hurley P. 2008a. TAPM V4. User manual. CSIRO Marine and Atmospheric Research Internal Report No. 5.

Hurley P. 2008b. TAPM V4. Part 1: Technical description. CSIRO Marine and Atmospheric Research Internal Report No. 5.

Hurley P, Edwards M, Luhar A. 2008. TAPM V4. Part 2: Summary of some verification studies. CSIRO Marine and Atmospheric Research Internal Report No. 26.

Hurley PJ, Physick WL, Luhar AK. 2005. TAPM: a practical approach to prognostic meteorological and air pollution modelling. Environmental Modelling \& Software 20:737752.

Jordan D, Smith W. 1994. Energy balance analysis of nighttime leaf temperatures and frost formation in a subalpine environment. Agricultural and Forest Meteorology 71:359-372.

King DA, Ball MC. 1998. A model of frost impacts on seasonal photosynthesis of Eucalyptus pauciflora. Australian Journal of Plant Physiology 25:27-37.

Köhler L, Gieger T, Leuschner C. 2006. Altitudinal change in soil and foliar nutrient concentrations and in microclimate across the tree line on the subtropical island mountain Mt. Teide (Canary Islands). Flora 201:202-214.

Körner C. 1998. A re-assessment of high elevation treeline positions and their explanation. Oecologia 115:445-459.

Körner C, Paulsen J. 2004. A world-wide study of high altitude treeline temperatures. Journal of Biogeography 31:713-732. 
630 Kullman L. 2005. Wind-conditioned 20th century decline of birch treeline vegetation in the 631 Swedish Scandes. Arctic 58:286-294.

632 Ledgard N, Davis M. 2004. Restoration of mountain beech (Nothofagus solandri var .

633 cliffortioides) forest after fire. New Zealand Journal of Ecology 28:125-135.

634 Leonelli G, Pelfini M, Cella U di. 2009. Detecting climatic treelines in the Italian Alps: The

635

636 influence of geomorphological factors and human impacts. Physical Geography 30:338352.

637 Liaw A, Wiener M. 2002. Classification and regression by randomForest. $R$ News 2:18-22.

638 Lindkvist L, Gustavsson T, Bogren J. 2000. A frost assessment method for mountainous areas.

639 Agricultural and Forest Meteorology 102:51-67.

640 Macias-Fauria M, Johnson E. 2013. Warming-induced upslope advance of subalpine forest is 641 severely limited by geomorphic processes. Proceedings of the ....

642 Malanson G. 2001. Complex responses to global change at alpine tree line. Physical Geography $643 \quad 22: 333-342$.

644

645

646

Malanson GP, Resler LM, Bader MY, Holtmeier F-K, Butler DR, Weiss DJ, Daniels LD, Fagre DB. 2011. Mountain treelines: a roadmap for research orientation. Arctic Antarctic and Alpine Research 43:167-177.

647

648

649

650

651

652

653

654

655

656

657

658

659

660

Martin TJ, Ogden J. 2006. Wind damage and response in New Zealand forests : a review. New Zealand Journal of Ecology 30:295-310.

Mocioaca G, Sivertsen B, Cuculeanu V. 2009. Three-dimensional wind field estimates in complex terrain. Romanian Reports in Physics 61:281-292.

Moore ID, Grayson RB, Ladson AR. 1991. Digital terrain modelling: a review of hydrological, geomorphological, and biological applications. Hydrological Processes 5:3-30.

Moyes AB, Castanha C, Germino MJ, Kueppers LM. 2013. Warming and the dependence of limber pine (Pinus flexilis) establishment on summer soil moisture within and above its current elevation range. Oecologia 171:271-82.

Piper FI, Cavieres LA, Reyes-Díaz M, Corcuera LJ. 2005. Carbon sink limitation and frost tolerance control performance of the tree Kageneckia angustifolia D. Don (Rosaceae) at the treeline in central Chile. Plant Ecology 185:29-39.

Rehm EM, Feeley KJ. 2015. Freezing temperatures as a limit to forest recruitment above tropical Andean treelines. Ecology 96:1856-1865. 
661 Sakai A, Wardle P. 1973. Freezing resistance of New Zealand trees and shrubs. New Zealand 662 Journal Of Ecology 1:51-61.

663 Sowell JB, McNulty SP, Schilling BK. 1996. The role of stem recharge in reducing the winter 664 desiccation of Picea engelmannii (Pinaceae) needles at alpine timberline. American Journal 665 of Botany 83:1351-1355.

666 Stirling M, Mc Verry G, Berryman K. 2002. A new seismic hazard model for New Zealand. 667 Bulletin of the Seismological Society of America 92:1878-1903.

668 Sturman AP, Tapper NJ. 2006. The Weather and Climate of Australia and New Zealand, Second 669 Edition. Oxford University Press, USA.

Tranquillini W. 1979. Physiological ecology of the alpine timberline. Tree existence at high altitudes with special reference to the European Alps. New York, NY: Springer-Verlag.

672

673

674

Vittoz P, Steward G, Duncan R. 2001. Earthquake impacts in old-growth Nothofagus forests in New Zealand. Journal of Vegetation Science:417-426.

Walsh SJ, Butler DR, Malanson GP, Crews-Meyer KA, Messina JP, Xiao N. 2003. Mapping, modeling, and visualization of the influences of geomorphic processes on the alpine treeline ecotone, Glacier National Park, MT, USA. Geomorphology 53:129-145.

Wardle P. 1981. Winter desiccation of conifer needles simulated by artificial freezing. Arctic and Alpine Research 13:419-423.

Wardle P. 1985a. New Zealand timberlines. 3. A synthesis. New Zealand Journal of Botany 23:219-234.

Wardle P. 1985b. New Zealand timberlines . 1 . Growth and survival of native and introduced tree species in the Craigieburn Range, Canterbury. New Zealand Journal of Botany 23:219-234.

Wardle P. 1985c. New Zealand timberlines . 2 . A study of forest limits in the Crow Valley near Arthur's Pass , Canterbury. New Zealand Journal of Botany 23:235-261.

Wardle P. 2008. New Zealand forest to alpine transitions in global context. Arctic Antarctic and Alpine Research 40:240-249.

Wardle JA, Allen RB. 1984. Dieback in New Zealand Nothofagus forests. Pacific Science 37:397-404. 
692 Wiegand T, Camarero JJ, Ruger N, Gutierrez E. 2006. Abrupt population changes in treeline 693 ecotones along smooth gradients. Journal of Ecology 94:880-892.

694 Wiser SK, Allen RB, Platt KH. 1997. Mountain beech forest succession after a fire at Mount 695 Thomas Forest, Canterbury, New Zealand. New Zealand Journal of Botany 35:37-41.

696 Wratt DS, Tait A, Griffiths G, Espie P, Jessen M, Keys J, Ladd M, Lew D, Lowther W, Mitchell 697 N, Morton J, Reid J, Reid S, Richardson A, Sansom J, Shankar U. 2006. Climate for crops: 698 integrating climate data with information about soils and crop requirements to reduce risks 699 in agricultural decision-making. Meteorological Applications 315:305-315.

700 Zevenbergen L, Thorne C. 1987. Quantitative analysis of land surface topography. Earth Surface $701 \quad$ Processes and Landforms 12:47-56.

702

703 


\section{FIGURES}

705 Figure 1. Location of the 28 study sites across New Zealand relative to broad climatic regions.

706 The inset (top left) shows one study area with treeline locations used for analyses, and the $200 \mathrm{~m}$

707 resolution, $7 \times 7 \mathrm{~km}$ grid across which meteorological outputs are generated by the TAPM model.

708 In the background of the inset is an example of a SPOT 5 satellite image used as a basis to verify

709 that treeline points were accurately located at treeline.

710

711 Figure 2. The distribution of treeline elevation deviations (m) from their study area maxima for

712 each of the 28 study areas examined in the study. The deviation values therefore reflect the

713 degree to which treeline elevations are lower than the site maximum (i.e. where the elevation

714 deviation equals zero).

715

716 Figure 3. Bi-plots of a principal components analysis (PCA) of meterological data generated at

717 southern beech treelines using the TAPM mesoscale atmospheric model. Bi-plots are shown for

718 principal components 1 and 2 (A), 1 and 3 (B), and 2 and 3 (C), which collectively explain

$71980.2 \%$ of the variation in the data. PCA eigenvectors are coloured according to the type of

720 meteorological variable; multiple vectors of the same colour occur when both maximum and

721 minimum conditions for that variable, for both January and July, are included. Dots represent

722 positions of the 28 study areas in ordination space, labelled with the site numbers and coloured

723 by their latitidinal position. See Table 1 for axis loadings for each variable.

725 Figure 4. Variable importance plot resulting from the random forest analysis of the effects of 17

726 explanatory factors on treeline elevation deviation across the 2100 treeline locations. The relative

727 importance score reflects the percent increase in mean square error that would result from the

728 removal of a given factor from the analysis.

729

730 Figure 5. Partial dependence plots, based on results from the random forest analysis, showing the

731 mean marginal influence of 12 explanatory variables on treeline elevation deviation. Each plot

732 represents the effect of each variable while holding the other variables constant. 
734 Figure 6. Conditional inference tree explaining treeline elevation deviation across 28 study areas 735 using the 12 most important explanatory factors determined from the random forest analysis. The 736 tree shows pathways of how the response data were recursively partitioned based on explanatory 737 variables. The observations associated with each terminal node are the result of these

738 partitionings. For example, Node 4 comprises treeline locations with a median treeline elevation 739 deviation of $250-\mathrm{m}$, characterised by an annual precipitation $<5,664-\mathrm{mm}$ and slope curvatures

740 less than -0.24. P-values at each node are from a Monte Carlo randomisation test; in order for a 741 split to occur p must be less than 0.05 .

743 Figure 7. Tile graph of the distribution of terminal nodes from the conditional inference tree for 744 all sampled treeline locations by site latitude and elevation. The terminal inference tree nodes 745 represent discrete recursive partitioning pathways in the conditional inference tree (see Figure 6).

746 Black points represent the mean treeline elevation at each study area.

\section{TABLES}

750

751 Table 1. Axis loadings for a principal components analysis of January and July hourly 752 meterological data generated by the TAPM model across treeline locations in this study.

753 Loadings greater or equal to 0.25 are shown in bold. 


\section{Table 1 (on next page)}

Table of PCA loadings 


\begin{tabular}{llll}
\hline TAPM-generated meteorological variable & PC1 & PC2 & PC3 \\
\hline January net outgoing long-wave radiation & $\mathbf{- 0 . 2 7}$ & 0.03 & -0.17 \\
January total solar radiation & $\mathbf{0 . 2 5}$ & -0.08 & 0.06 \\
July net outgoing long-wave radiation & $\mathbf{- 0 . 3 5}$ & -0.03 & 0.11 \\
July total solar radiation & $\mathbf{0 . 2 8}$ & -0.17 & -0.11 \\
January rain days & $\mathbf{- 0 . 2 9}$ & -0.14 & -0.02 \\
July rain days & $\mathbf{- 0 . 3 1}$ & -0.13 & 0.16 \\
July minimum relative humidity & $\mathbf{- 0 . 3 2}$ & -0.06 & 0.02 \\
July maximum relative humidity & $\mathbf{- 0 . 3 1}$ & -0.14 & -0.04 \\
January minimum relative humidity & $\mathbf{- 0 . 2 7}$ & $\mathbf{- 0 . 2 3}$ & -0.12 \\
January maximum relative humidity & $\mathbf{- 0 . 2 6}$ & $\mathbf{- 0 . 2 7}$ & -0.15 \\
January minimum temperature & -0.14 & $\mathbf{0 . 3 8}$ & 0.03 \\
January maximum temperature & -0.02 & $\mathbf{0 . 3 8}$ & -0.03 \\
July minimum temperature & -0.14 & $\mathbf{0 . 3 9}$ & 0.05 \\
July maximum temperature & -0.03 & $\mathbf{0 . 4 2}$ & -0.06 \\
January frost hours & 0.21 & $\mathbf{- 0 . 2 7}$ & -0.05 \\
July frost hours & 0.14 & $\mathbf{- 0 . 2 2}$ & $\mathbf{- 0 . 3 6}$ \\
January minimum wind speed & 0.13 & -0.05 & $\mathbf{0 . 4 1}$ \\
January maximum wind speed & 0.12 & -0.03 & $\mathbf{0 . 4 4}$ \\
July minimum wind speed & -0.07 & -0.14 & $\mathbf{0 . 4 3}$ \\
July maximum wind speed & -0.06 & -0.12 & $\mathbf{0 . 4 3}$ \\
\hline
\end{tabular}




\section{1}

Map showing location of study areas across New Zealand

The main map shows study sites across New Zealand. The inset figure shows one study site overlain by $7 \times 7 \mathrm{~km}, 200-\mathrm{m}$ resolution grid across which meterological data were generated by the TAPM model.

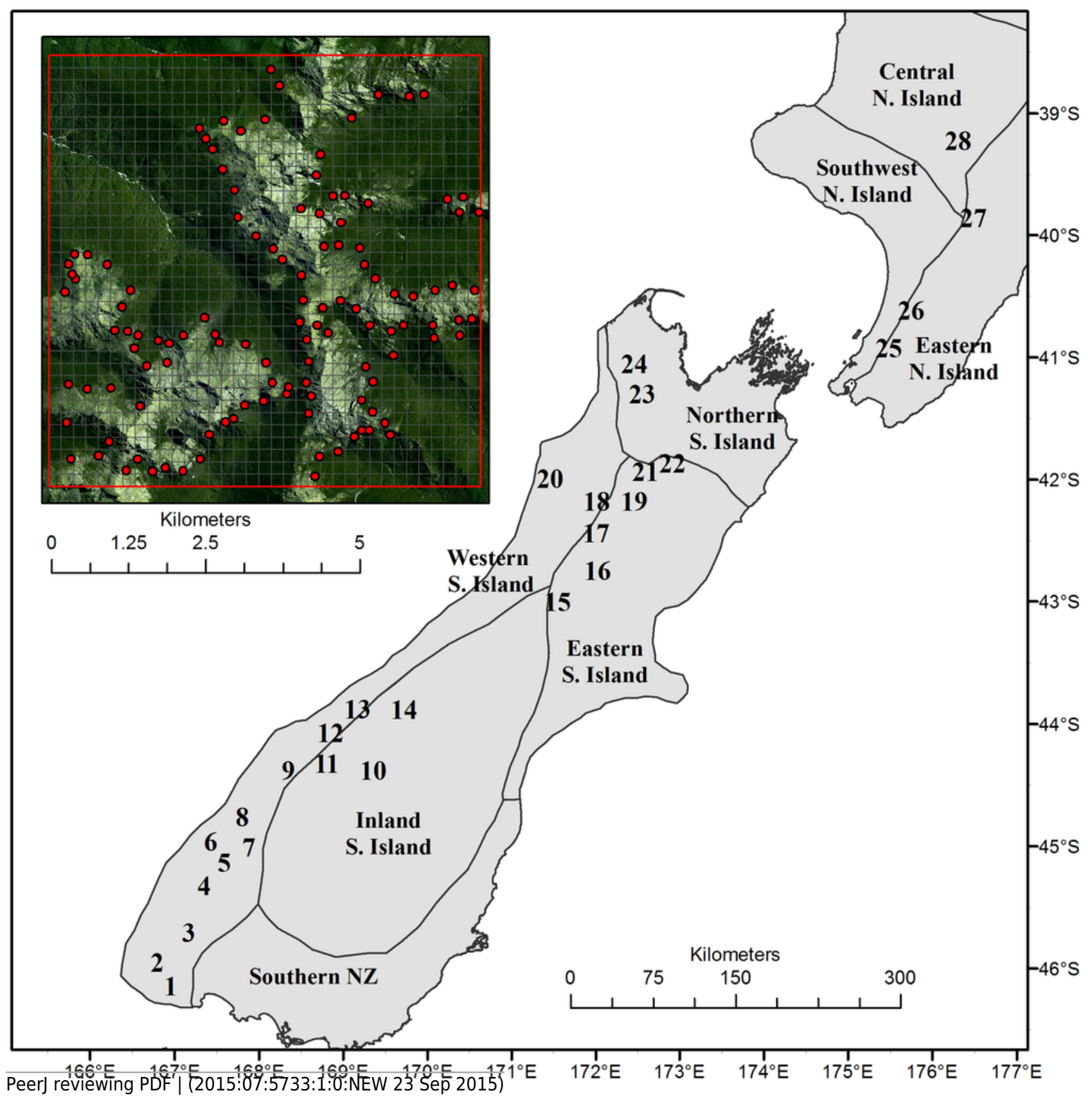


2

Box plots showing variability in the deviations of treeline elevations from their potential site-level maximum elevations.

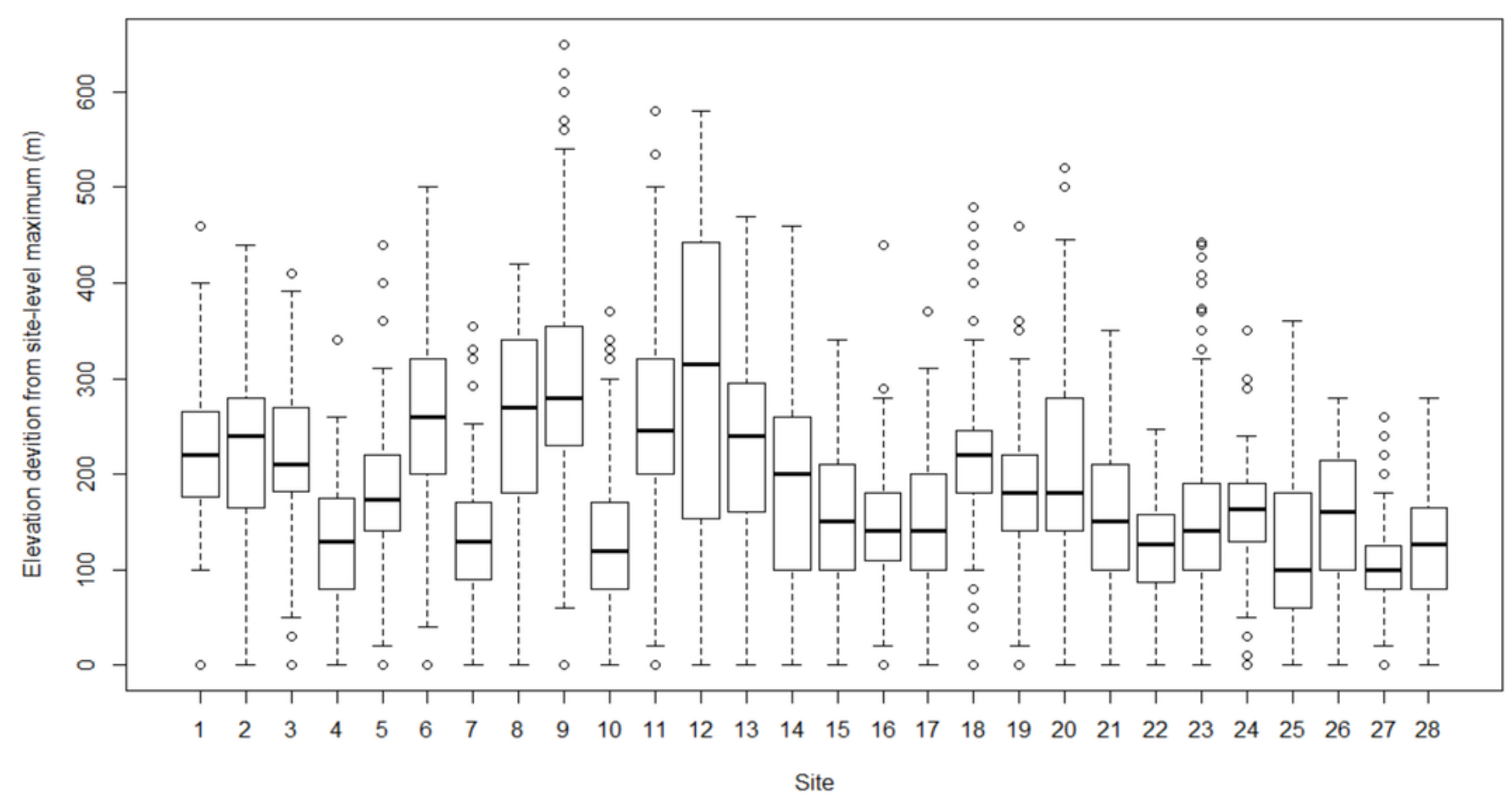




\section{3}

PCA bi-plots of TAPM-generated meteorological data.

Eigenvectors for TAPM-generated meterological variables are shown, coloured according to the type of variable (temperature, humidity, wind speed, radiation, frost days, rain days). Dots represent sites, and are coloured according to their latitude.

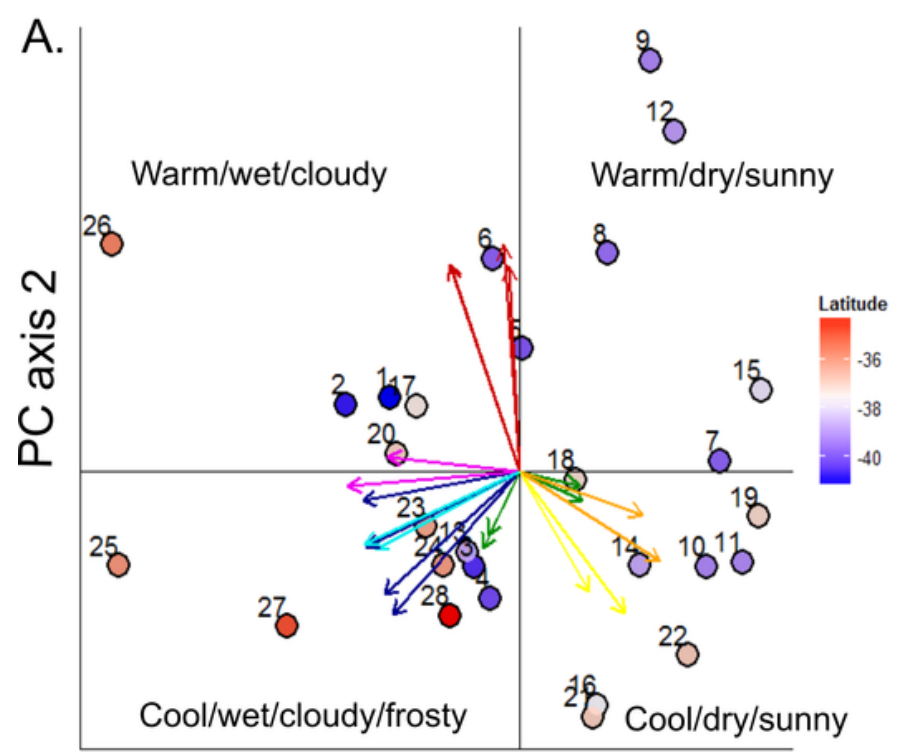

PC axis 1

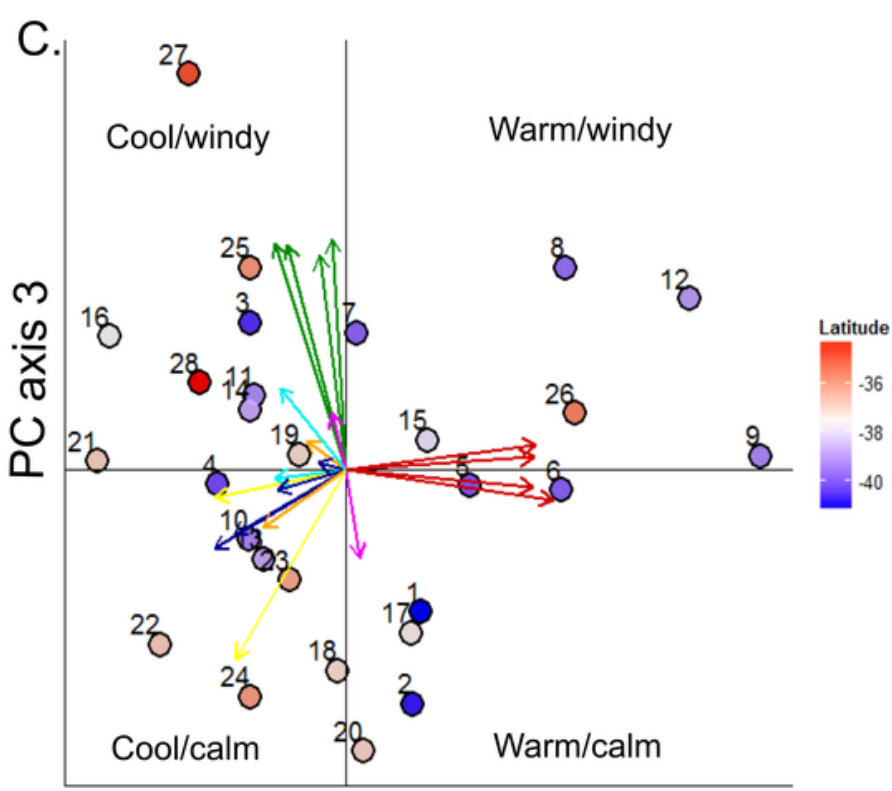

$\mathrm{PC}$ axis 2

Peer] reviewing PDF | (2015:07:5733:1:0:NEW 23 Sep 2015)

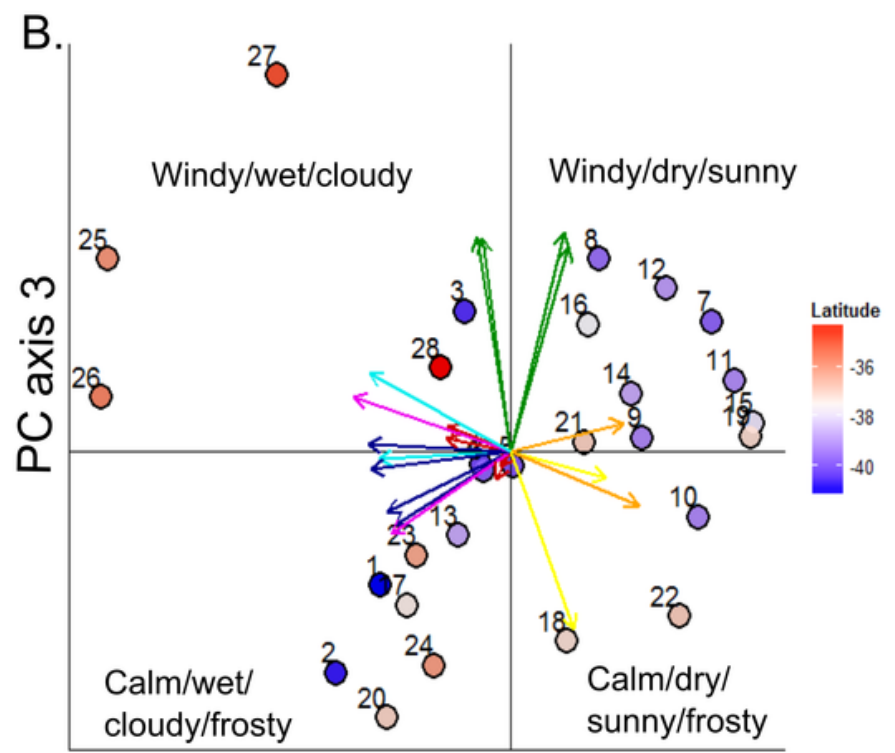

\section{$\mathrm{PC}$ axis 1}

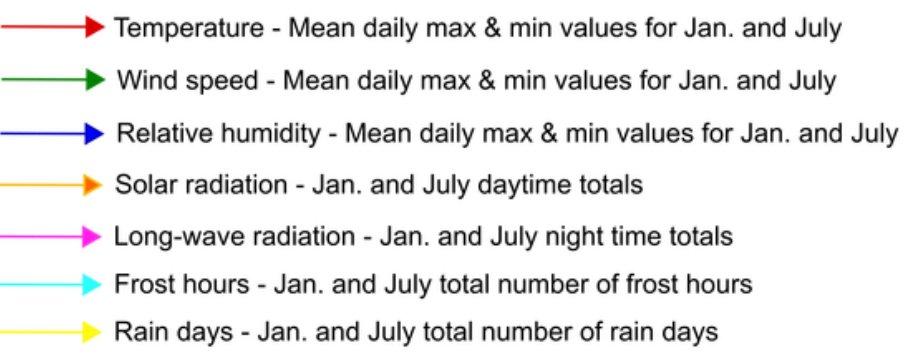


4

Variable importance plot showing relative importance of each of 17 variables entered into the random forest analysis.

Curvature

Annual_precip

Jan_desiccation_index

Slope

July_desiccation_index

July_frost_index

Jan_insolation

July_photoinhibition_index

Jan_photoinhibition_index

GS_temperature

July_insolation

Jan_frost_index

Earthquake_intensity

Topographic_variation_index

Erosion_index

Winter_temperature

Mountain_mass

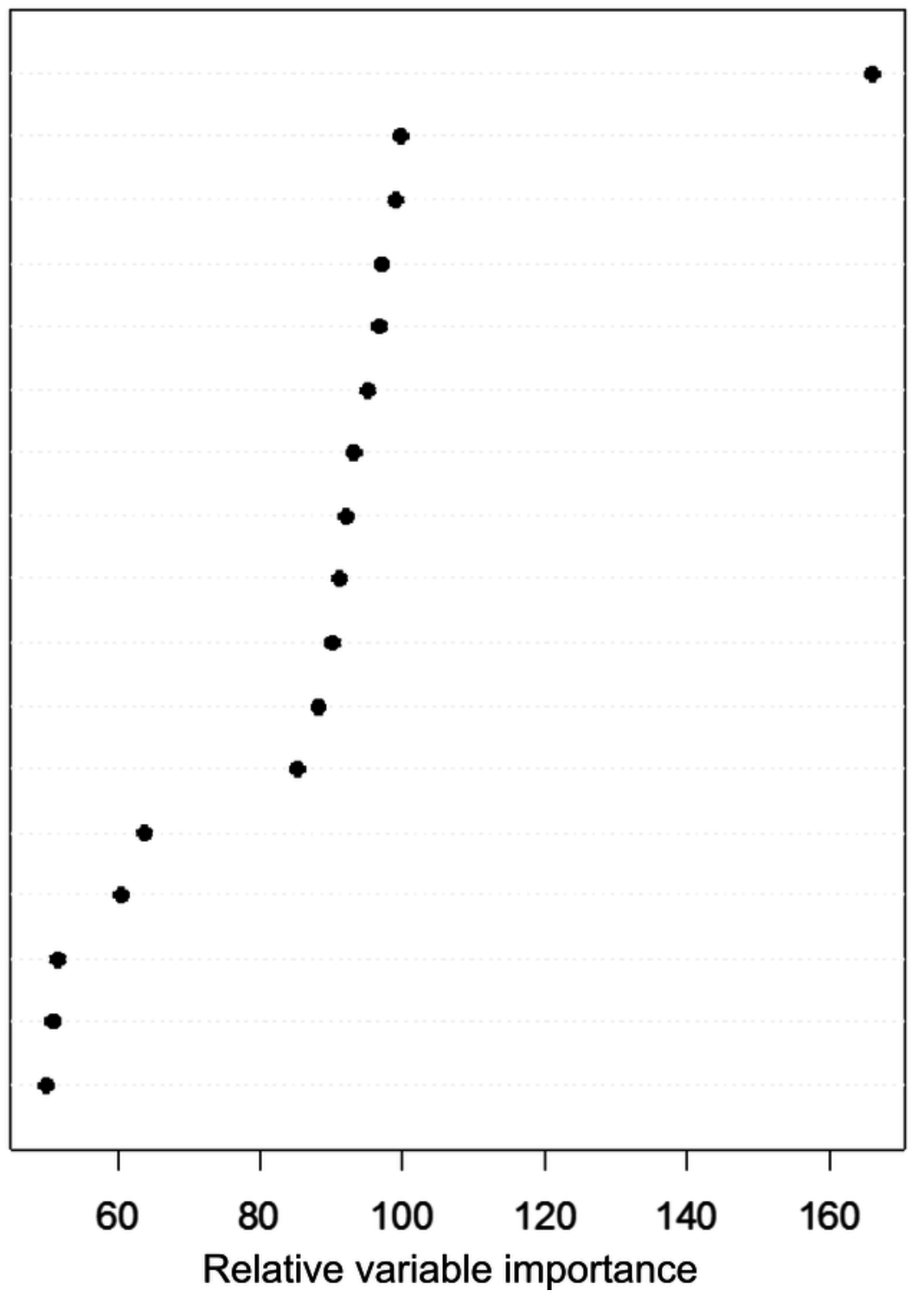


5

Partial dependence plot results from the random forest analysis showing marginal relationships between treeline elevation deviation (response variable) and the 12 topranked explanatory variables.
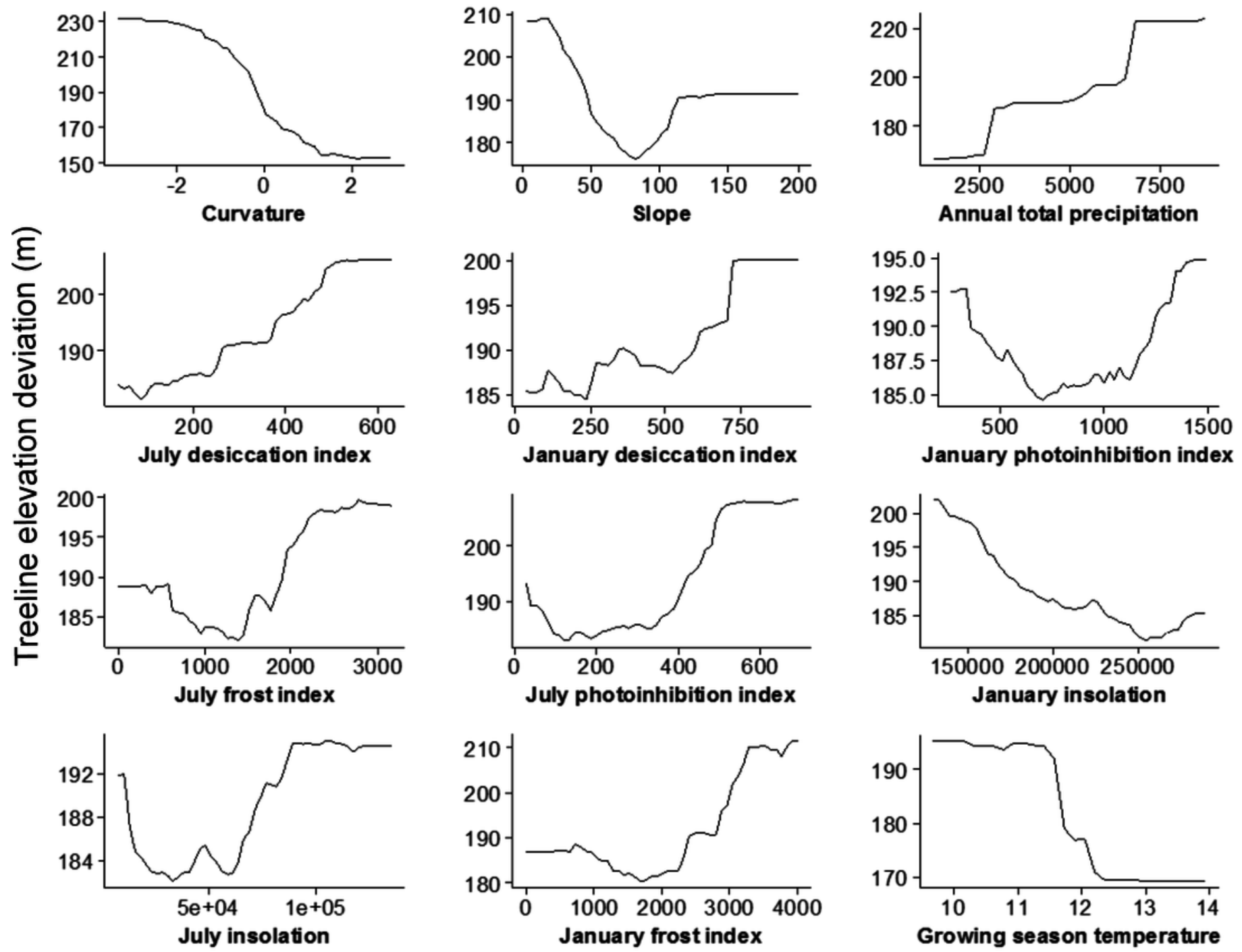
6

Dendrogram from conditional inference tree analysis.

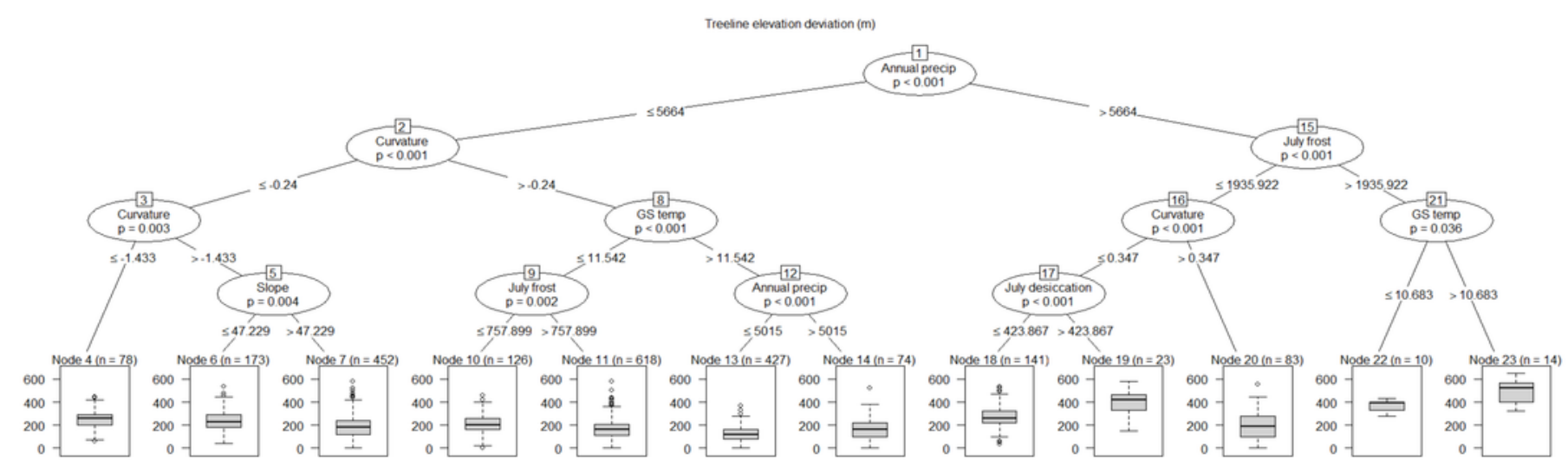


7

Tile plot of conditional inference tree terminal nodes plotted for each treeline location in relation to their latitude ( $x$ axis) and their treeline elevation.

Each observation is coloured according to the terminal node from the conditional inference tree with which it's associated.

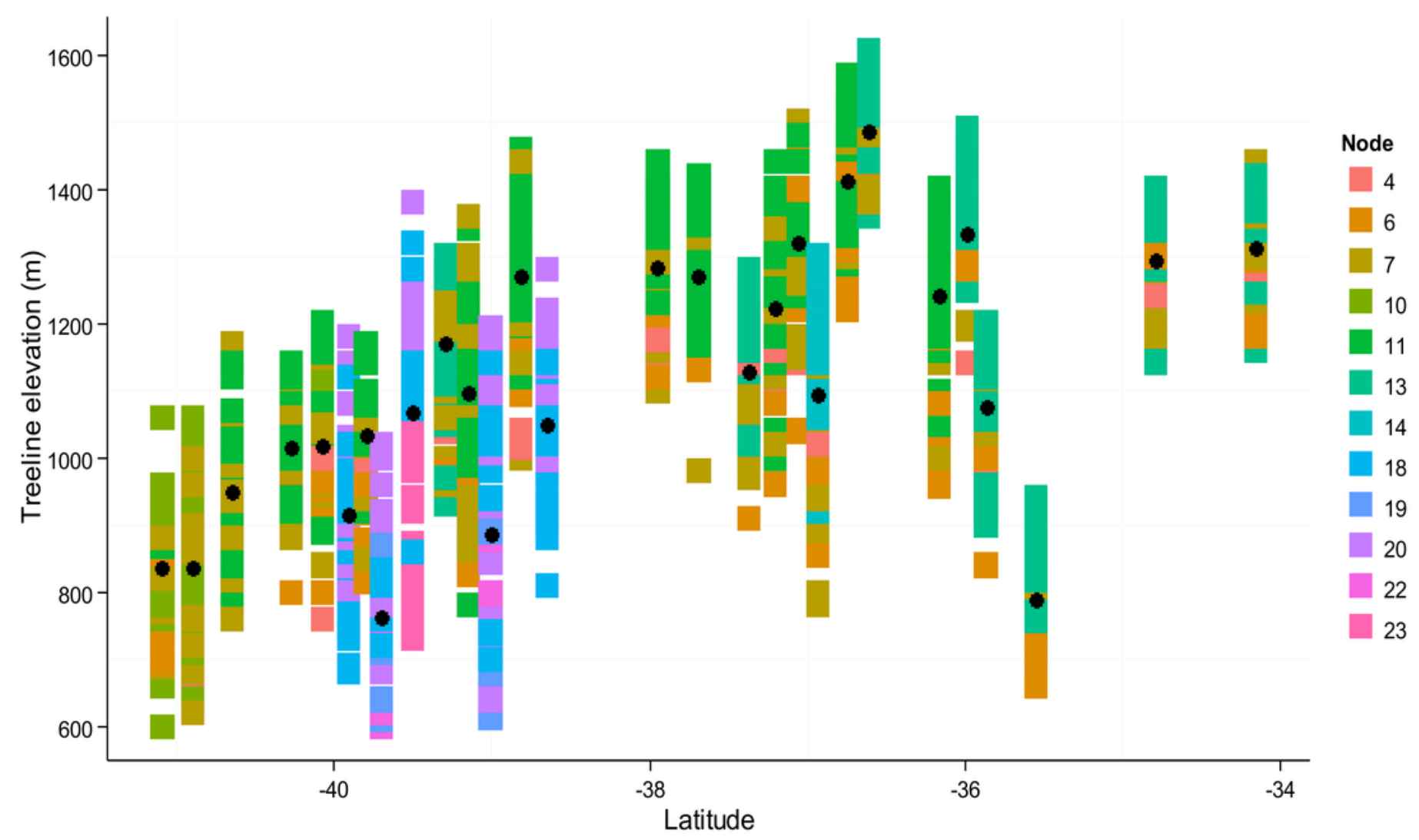

